\title{
Türkiye'deki Buğday Üretimine Kantitatif Bir Yaklaşım
}

\author{
Kübra Tümay Ateş ${ }^{1 *}$ \\ 1* Çukuorva Üniversitesi, Mühendislik Fakültesi, Endüstri Mühendisliği Bölümü, Adana, Türkiye, (ORCID: 0000-0002-3337-7969), ktumay@,cu.edu.tr
}

(Uluslararası Araştırma-Geliştirme ve Tasarım Konferansı - 15-18 Aralık 2021)

(DOI: 10.31590/ejosat.1039919)

ATIF/REFERENCE: Tümay Ateş, K. (2021). Türkiye'deki Buğday Üretimine Kantitatif Bir Yaklaşım. Avrupa Bilim ve Teknoloji Dergisi, (32), 235-240.

$\ddot{O} \mathbf{z}$

Son dönemlerin en büyük sorunlarından biri olan yağışın azlığı beraberinde tarımsal üretimlerde zayıflamaları getirmiştir. Türkiye geneline bakıldığında son yılların çok kurak geçtiği görülmektedir. Kuraklıkların artması çifţinin sulama suyunu elde etme imkanını azaltmış, artan girdi maliyetleri gübrenin ve sarf malzemelerin temin edebilmesini oldukça zorlaştırmıştır. Bu durum dolaylı yoldan da olsa devletin kaynaklarını da etkilemektedir. $\mathrm{Bu}$ ve bunun gibi sebeplerden dolayı buğdayın geçmiş yıllara göre üretimi azalmış ve maliyeti de artmıştır. Bu kapsamda gelecek yıllar için tahmin verileri de buğday üretiminin azalacağ yönündedir. Tüm bunlar göz önüne alınarak, buğdayın üretimini etkileyen parametreler Türkiye İstatistik Kurumu (TÜIK), Tarım ve Orman Bakanlığı (TOB) ve Toprak Mahsulleri Ofisi (TMO)'dan elde edilmiştir. Elde edilen bilgiler doğrultusunda buğday üretiminin hangi parametrelerle daha çok ilişkili olduğu temel bileşen analizi kullanılarak açıklanmıştır. Aynı zamanda etki parametrelerinin dolaylı olarak buğday üretimine etkisinin olup olmadığı korelasyon analizi ile araştırılmıştır. Buğday üretiminin azalmasına sebep olabilecek faktörler kantitatif olarak değerlendirilmiştir.

Anahtar Kelimeler: Temel Bileşen Analizi, Korelasyon Analizi, Parametre Belirleme.

\section{A Quantitative Approach to Wheat Production in Turkey}

\begin{abstract}
The scarcity of precipitation, which is one of the biggest problems of recent times, has brought with it a weakening in agricultural production. Looking at Turkey in general, it is seen that the last years have been very dry. Increasing droughts have reduced the farmer's ability to obtain irrigation water, and increasing input costs have made it very difficult to obtain fertilizer and consumables. This situation affects the resources of the state, albeit indirectly. Due to these and similar reasons, the production of wheat has decreased compared to previous years and its cost has increased. In this context, the estimation data for the coming years is that wheat production will decrease. Considering all these, the parameters affecting the wheat production were obtained from the Turkish Statistical Institute, the Ministry of Agriculture and Forestry and the Turkish Grain Board .In line with the information obtained, it was explained by using principal component analysis with which parameters wheat production is more related. At the same time, whether the effect parameters have an indirect effect on wheat production was investigated by correlation analysis. The factors that may cause a decrease in wheat production were evaluated quantitatively.
\end{abstract}

Keywords: Principal Component Analysis, Correlation Analysis, Parameter Determination.

\footnotetext{
*Sorumlu Yazar: ktumay@cu.edu.tr
} 


\section{Giriş}

Son yıllarda kuraklığın artması tarımsal üretim açısından bir çok farklı çözüm arayışı doğurmuştur. Bunlar, üretici, tüketici ve devlet temelli yapılandırmalar ve koşulların mümkün olduğunca iyileştirilmesi yönündedir. Türkiye istatistik kurumunun tarımsal üretim istatistiklerine bakıldığında; 2020 yılında bir önceki yıla göre tahıl ürünleri \%8,7 oranında artış gösterirken, üretim miktarları 2020 yılında yaklaşık olarak 69,3 milyon ton olarak gerçekleşmiştir. 2021 yılının üretim miktarlarının yılının ikinci tahmininde ise bir önceki yıla göre tahıllar azalacağı öngörülmüştür. Buna göre üretim miktarlarının 2021 yılında yaklaşık olarak tahıllar ve diğer bitkisel ürünlerde 62,7 milyon ton olabileceği öngörülmüştür [1,2]. Burada söz konusu olan buğdayın üretim miktarının hangi parametrelere bağlı olduğunu kantitatif metotlarla belirleyebilmektir. Çalışmada kullanılan metotlara bakıldığında çok farklı alanlarda yapılmış çalışmalara rastlanmıştır;

Chen vd., sulama suyu tüketimini etkileyen ana faktörleri belirlemek için entegre bir yaklaşım ortaya koymuştur. Sulama suyu tüketimi ile etkileyen faktörler arasındaki ilişkiyi analiz etmek için çoklu doğrusal regresyon ve temel bileşen analizini birleştirmiştir. Ayrıca sulama suyu tüketiminin itici faktörlerindeki uzamsal değişimi analiz etmek için analitik hiyerarşi sürecini ve küme analizini uygulamıştır [3]. Li ve Huang, çalışmalarında yapısal hasarların doğru bir şekilde tanımlanmasını sağlayabilmek ve çapraz korelasyon fonksiyonları tarafindan oluşturulan özellik vektöründen yapısal durumu tanımlamak için PCA tabanlı bir yaklaşım önermiştir [4]. Xu vd., çalışmalarında asfaltın konvansiyonel, reolojik özellikleri, kimyasal yapısını test etmiştir. Değerlendirme göstergeleri arasındaki karşılıklı etkiyi ortadan kaldırmak için temel bileşen analizi (PCA) kullanılmıştır [5]. Wang vd., COVID-19'un ham petrol ve tarımsal vadeli işlem piyasaları arasındaki etkileşimi çapraz korelasyon yöntemi ile araştırarak sonuçları yorumlamıştır [6]. Zhang vd., çalışmalarında piroliz sıcaklığının ve korelasyon analizinin mahsul kalıntısı olan biyokömürün verim ve fizikokimyasal özellikleri üzerindeki etkisini araştırmıştır. Korelasyon analizinin etkinliği sonuçlarla tartışılmıştır [7]. Utrilla-Vázquez vd., çalışmalarında beş çeşit ince aromalı kakao türünün uçucu bileşiklerini tanımlamayı amaçlayan bir analiz yapmıştır. Fermantasyon ve kurutma işlemi sırasında her bir kakao türünden uçucu bileşiklerin profili elde edilmiştir. Uçucu bileşiklerin, Venn diyagramının istatistiksel analizi ve Temel Bileşenlerin Çok Değişkenli Analizi (PCA) kullanılarak fermente edilmemiş fasulye ile karşılaştırılmıştır [8]. Zhang vd., elma hasadında temel bileşenlerin katsayılarını hesaplamak veelma hasadında temel gölgelik parametrelerini belirlemek için temel bileşenler analizinden yararlanmıştır [9]. Petkovic vd., tarımsal biyokütlenin enerjisinden etkin bir şekilde yararlanmak için bir çalışma yapmıştır. Çalışmalarında tarımsal tahmin modeli geliştirebilmek için ANFIS modeline entegre olarak temel bileşen analizi kullanılmıştır. Elde edilen sonuçlar, tarımsal biyokütlenin kompozit elementi olarak hidrojene dayalı standart entropi için en iyi tahmin performanslarını göstermiştir [10]. Yağmur ve Güneş, organik tarımda bitki gelişimini destekleyen rhizobacterianın domates bitkilerinin verim ve kalite parametreleri üzerindeki etkilerinin temel bileşen analizi ile değerlendirmiştir [11].

Literatür incelendiğinde, problemlerin analizi ve bu problemlere etki eden faktörlerin belirlenebilmesi için temel bileşen analizi ve korelasyon analizinin benzer ve farkl alanlarda kullanıldığı görülmektedir.

\section{Materyal ve Metot}

\subsection{Deneysel Tasarım ve Veri Analizi}

Çalışmada, Buğday üretimi için önemli olan parametreler TÜİK ve TOB'nin 5 yıllık istatistiksel verileri ile belirlenmiştir. Öncelikle verilerin tanımlayıcı analizi yapılmış daha sonra Temel Bileşen Analizi ve Korelasyon analizleri ile Buğday üretimi için etkili parametrlerin analizleri yapılmıştır.

\subsubsection{Temel Bileşen Analizi (TBA)}

Temel bileşen analizi (TBA), Pearson tarafından geliştirilen ve bilgileri çok fazla kaybetmeden ortogonal dönüşüm kullanarak bir dizi ilişkili özelliği doğrusal olarak ilişkisiz değişkenlerin bir dizi değerine dönüştüren boyutluluğu azaltmaya yönelik bir yaklaşımdır. Temel bileşenler adı verilen dönüşüm biçimi, mümkün olan en büyük varyanstan mümkün olan en düşük olasılığa doğru sıralanır [12]. Bu çalışmada, TBA buğday üretimini etkileyen faktörlerin analizi için korelasyon analizi ile birleştirilmiştir.

\subsubsection{Korelasyon Analizi}

Korelasyon analizi iki veya daha fazla bileşen arasında bir ilişki veya bağlantı kurma sürecidir. Ayrıca iki rastgele değişken veya iki değişkenli veri arasındaki neden olup olmadığına bakılmaksızın kurulan istatistiksel bir ilişkidir [13]. Pearson korelasyon analizi, değişkenler arasındaki korelasyonu ölçmek için yaygın olarak kullanılan bir kriterdir ve Denklem (1)'deki şekilde tanımlanır [14]:

$$
R(i)=\frac{\sum_{k=1}^{m}\left(x_{k, i}-x \prime\right)\left(y_{k}-y^{\prime}\right)}{\sqrt{\sum_{k=1}^{m}\left(x_{k}-x^{\prime}\right)^{2}\left(y_{k}-y^{\prime}\right)^{2}}}
$$

Burada m örneklem sayısı olduğunda, R(i) i. özelliği ile sınıf standardı arasındaki korelasyonu ölçer. $x_{k, i}$, k örneğinin i. özelliğinin değeridir. $\mathrm{X}_{\mathrm{i}}^{\prime}$, i özelliğinin ortalama değeridir. $\mathrm{y}_{\mathrm{k}}, k$ örneğinin değerini temsil eder ve y', $k$ örneğinin sınıf standardı ortalama değerini temsil eder.

Denklem (1)'e göre, R(i)'nin varyasyon aralığı -1 ile 1 arasındadır. $\mathrm{R}(\mathrm{i})=1$ olduğunda, i özelliği sınıf standardı ile pozitif olarak doğrusal ilişkilidir; R ( i) = 1- olduğunda, i özelliği sınıf standardı ile negatif doğrusal ilişkilidir. i özelliği ile sınıf standardı arasındaki korelasyon derecesi değiştikçe, R(i) değeri 0 ile 1 arasında değişmektedir. R(i)değeri ne kadar büyükse, i özelliğinin sınıflandırmaya katkısı o kadar fazladır. R(i) $<0.3$ olduğunda, özellikler ve sınıf standardı arasında zayıf bir korelasyon olduğunu göstermektedir. $0,3<\mathrm{R}(\mathrm{i})<0,5$ olduğunda özellikler ve sınıf standardı arasında düşük bir korelasyon olduğu söylenebilir. $0,5<\mathrm{R}(\mathrm{i})<0,8$ olduğunda ise özellikler ve sınıf standardı arasında yüksek bir korelasyon olduğu söylenir $[14,15]$. 


\section{Araştırma Sonuçları ve Tartışma}

\subsection{Parametrelere Ait Veriler ve Tanımlayıcı İstatistikler}

Buğday üretimini etkileyen parametreler, Buğday miktarının gübreye oranı, Destekli Buğday miktarının gübreye oranı, Buğday miktarının mazota oranı, Destekli buğday miktarının mazota oranı, Buğday miktarının tohum miktarına oranı, Destekli buğday miktarının tohum miktarına oranı, verim $(\mathrm{kg} / \mathrm{da})$, yıllık buğday tüketimi (bin ton) olmak üzere belirlenmiştir. Elde edilen sekiz parametre TÜIK, TOB ve TMO 'dan elde edilmiştir (Tablo 1).

Tablo 2 incelendiğinde buğday üretimine etki eden parametrelerin ortalama ve standart sapmaların normal sinırlarda olduğu görülmüştür.

Tablo 2. Buğday Üretim Miktarını Etkileyen Parametrelerin Tanımlayıcı İstatistikleri

\begin{tabular}{lrll}
\hline Parametreler & Ortalama & Std.Sapma Gözlemler \\
\hline BugdayGubreOrani & 0,550 & 0,07000 & 5 \\
BugdayveDestek_GubreOrani & 0,640 & 0,08396 & 5 \\
Bugday_MazotOrani & 0,204 & 0,03130 & 5 \\
BugdayveDestek_MazotOrani & 0,216 & 0,02608 & 5 \\
BugdayTohumOrani & 0,576 & 0,03912 & 5 \\
BugdayveDestekTohumOrani 0,674 & 0,05177 & 5 & \\
StokDegisimi & 0,071 & 528,215 & 5 \\
BugdayinTuketimMiktari & 18933 & 713,616 & 5 \\
Verim & 266,4 & 15,72578 & 5 \\
\hline
\end{tabular}

\subsection{Buğdayın Üretim Parametrelerine Ait Korelasyon Analizi}

Buğday üretimini etkileyen parametrelerin birbiriyle olan ilişkisi korelasyon analizi ile elde edilmiştir. Tablo 3 . incelendiğinde Buğday/Gübre oranının, Buğday + Destek/Gübre oranı ile 0,99 korelasyon katsayısı ile pozitif yönde bir ilişkisi olduğu görülmüştür. Buğday/Gübre parametresinin ise Buğday/Mazot oranı ile - 0,53 korelasyon katsıyısı ile negatif yönde ilişkisi olduğu tespit edilmiştir. Böylelikle, buğday gübre oranı arttığında buğday mazot oranı azalacaktır. Buğday/Gübre oranının stok değişimi ile 0.80 oranında pozitif ilişkili olduğu görülmüsstür. Stok arttığında buğday/gübre oranı da artacaktır denilebilir. Aynı şekilde Buğday + Destek/Gübre oranı ile Stok değişimi arasında 0,81 korelasyon katsayısı ile pozitif yönlü bir ilişki içinde olduğu görülmüştür. Buğday/Tohum oranı ile buğdayın tüketim miktarı arasında $-0,65$ düzeyinde negatif yönlü bir ilişki olduğu saptanmıştır. Burada Buğday/tohum oranı arttığında tüketim miktarının azalacağı söylenebilmektedir. Buğday + Destek/Mazot oranı ile stok değişimi arasında $-0,83$ değerinde nagatif bir ilişki görülmüştür. Ayrıca Buğday + Destek/Mazot oranı ile buğdayın tüketimi arasında 0,58 değerinde pozitif bir korelasyon mevcuttur. Aynı zamanda, Buğday + Destek/Gübre oranını ve Buğday /Gübre oranların artmas1 verimi pozitif yönde etkilediği görülmüştür. Buğday/Tohum oranı, Buğday+ Destek /Tohum oranı ile stok miktarının artması durumunda Buğdayın tüktim miktarı azalmaktadır.

\subsection{Buğdayın Üretim Parametrelerine Ait Temel Bileşen Analizi}

Buğdayın üretiminde etkili olan parametrelerin geçerliliğini tespit etmek ve faktör yapısını anlamak amacıyla temel bileşen analizi (TBA) yapılmışır. Doğrudan eğik döndürma metodu kullanılarak yapılan TBA sonucunda buğday üretimini etkileyen 9 parametrenin 2 faktörlü bir yapıdan oluştuğu Tablo 4'deki gibi tespit edilmiştir. Aynı zamanda bu 2 faktör toplam varyansın \% 81,64'ünü açıkladığı görülmüştür. Bu durum buğday üretimi için yapılan TBA sonucunun geçerli olduğunu göstermektedir. Faktörlerin alt boyutlarına bakıldığında, ilk faktörün varyansı \% 53 oranında açıkladığı ikinci faktör ise \% 28,64 oranında açıkladığı görülmüştür.

Tablo 5. Buğday üretimini etkileyen parametrelerin alt faktör boyutlarına göre etki değerleri

\begin{tabular}{lcc}
\hline & \multicolumn{2}{c}{ Bileşenler } \\
& $\mathbf{1}$ & $\mathbf{2}$ \\
\hline BugdayGubreOrani &, 831 & \\
BugdayveDestek_GubreOrani &, 894 & \\
Bugday_MazotOrani &,- 536 & \\
BugdayveDestek_MazotOrani &,- 721 &, 948 \\
BugdayTohumOrani & &, 958 \\
BugdayveDestekTohumOrani & & \\
StokDegisimi &, 922 & \\
BugdayinTuketimMiktari &,- 870 \\
Verim &, 845 \\
\hline
\end{tabular}

Tablo 5'te ise buğday üretimini etkileyen parametrelerin alt faktör boyutlarına göre etki değerleri görülmektedir. Burada ilk alt boyutta 7 parametre gözlenirken, 2. Alt boyutta 2 parametre gözlenmiştir. Faktörlerin en düşük etkisi -0,53 iken en yüksek etkisi 0,95 olarak elde edilmiştir. Faktör yüklerinin 0,40 'dan büyük olması, parametrelerin faktörler üzerinde etkili olduğunu göstermektedir [16].

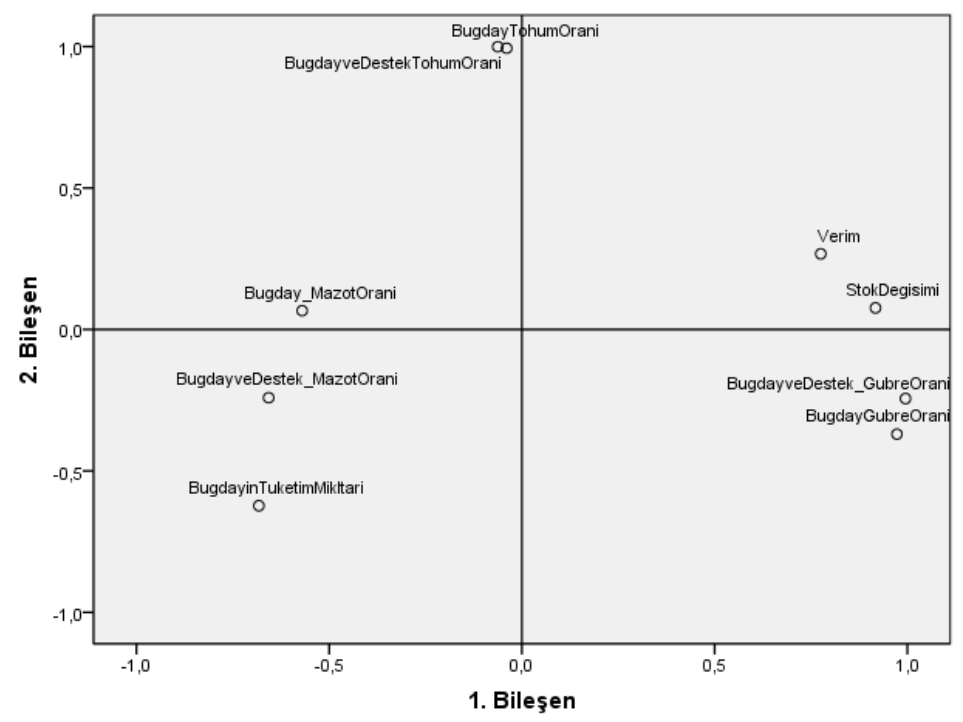

Şekil 1. Alt faktör boyutlarına ait parametreler 
Şekil 1.'de parametrelerin hangi alt faktör bileşen grubunda olduğu görülmektedir. Buna göre Buğday/Gübre oranı, Buğdayın tüketim miktarı, verim, stok değişimi, Buğday/ Mazot oran1, Bugday+Destek/ Gubre oran1, Bugday+ Destek/Mazot oranı ilk alt bileşende yer alırken, Buğday/tohum oranı ve Buğday+Destek/tohum oranı ikinci alt bileşende yer aldığı görülmektedir.

\section{Sonuç}

Çalışmanın sonuçları incelendiğine buğday üretimini etkileyen faktörlerin analizi ile parametrelerin birbiri ile olan ilişsisi ortaya konmuştur. Dolayısıyla iki alt boyuta indirgenen faktörlerin \% 81,64 oranı ile buğday üretimini etkilediği söylenebilir. Korelasyon analiz ile parametrelerin birbiri ile olan ilişkileri ortaya konmuş ve parametrelerin azalması veya artması durumunda ortaya çıkabilecek sonuçların buğday üretimi üzerindeki etkileri irdelenmiştir. Buna göre;

- Buğday+ Destek /Gübre oranı arttıkça Buğday/Gübre oranı da artabilecektir.

- Buğday/Gübre oranının artması buğday stoğunun artmasına sebep olabilecektir.

- Bugday + Destek/ Mazot oranının artması buğday tüketimini arttırabilecektir.

- Buğday/Gübre oranının artması buğday verimini arttırabilecektir.

- Buğday+ Destek /Gübre oranı arttıkça buğday verimi de artabilecektir.

- Buğday/Tohum oranının artması buğdayın tüketim miktarını azaltabilecektir.

- Bugday/ Mazot oranının artması buğday stoğunu azaltabilecektir.

- Bugday +Destek/ Mazot oranının oranının artması buğday stoğunu azaltabilecektir. 
European Journal of Science and Technology

Tablo 1. Buğday Üretim Miktarını Etkileyen ParametrelerinTanımlayıcı İstatistikleri[1,2]

\begin{tabular}{lcccccc}
\hline & \multicolumn{7}{c}{ Yllar } \\
\hline $\begin{array}{l}\text { Buğday Üretimini Etkileyen } \\
\text { Parametreler }\end{array}$ & $\mathbf{2 0 1 6}$ & $\mathbf{2 0 1 7}$ & $\mathbf{2 0 1 8}$ & $\mathbf{2 0 1 9}$ & $\mathbf{2 0 2 0}$ \\
\hline $\begin{array}{l}\text { Buğday/Gübre oranı } \\
\text { Buğday+Destek/Gübre oranı }\end{array}$ & 0,46 & 0,62 & 0,62 & 0,51 & 0,54 \\
Buğday/Mazot oranı & 0,52 & 0,72 & 0,72 & 0,61 & 0,63 \\
Buğday+Destek/Mazot oranı & 0,22 & 0,19 & 0,17 & 0,19 & 0,25 \\
Buğday/Tohum orani & 0,25 & 0,23 & 0,19 & 0,22 & 0,29 \\
Buğday+Destek/Tohum oranı & 0,55 & 0,54 & 0,57 & 0,64 & 0,58 \\
StokDegisimi (bin ton & 0,64 & 0,63 & 0,66 & 0,76 & 0,68 \\
Buğdayın Tüketim Miktarı (bin ton) & -744 & $-2,167$ & 750 & $-1,311$ & $-2,167$ \\
Verim (kg/da) & 20122 & 18795 & 18756 & 18187 & 18805 \\
\hline
\end{tabular}

Tablo 3. Buğdayın Üretim Parametrelerine Ait Korelasyon Analizi

\begin{tabular}{|c|c|c|c|c|c|c|c|c|c|}
\hline & $\begin{array}{c}\text { BugdayGub } \\
\text { reOrani }\end{array}$ & $\begin{array}{c}\text { BugdayveDestek } \\
\text { GubreOrani }\end{array}$ & $\begin{array}{c}\text { Bugday_Maz } \\
\text { otOrani }\end{array}$ & $\begin{array}{c}\text { BugdayveDestek } \\
\text { MazotOrani }\end{array}$ & $\begin{array}{c}\text { BugdayTohu } \\
\text { mOrani }\end{array}$ & $\begin{array}{c}\text { BugdayveDestekT } \\
\text { ohumOrani }\end{array}$ & $\begin{array}{l}\text { StokDe } \\
\text { gisimi }\end{array}$ & $\begin{array}{c}\text { BugdayinTuketi } \\
\text { mMikltari }\end{array}$ & $\begin{array}{l}\text { Ver } \\
\text { im }\end{array}$ \\
\hline BugdayGubreOrani & 1,000 & 991 &,- 536 &,- 520 &,- 292 &,- 310 & ,807 &,- 490 & ,68 \\
\hline $\begin{array}{l}\text { BugdayveDestek } \\
\text { GubreOrani }\end{array}$ & ,991 & 1,000 &,- 552 &,- 559 &,- 167 &,- 184 & ,841 &,- 602 & $\begin{array}{r}, 76 \\
3\end{array}$ \\
\hline $\begin{array}{l}\text { Bugday_MazotOra } \\
\text { ni }\end{array}$ &,- 536 &,- 552 & 1,000 &,- 006 &,- 086 &,- 059 &,- 566 & ,353 & $\begin{array}{r}- \\
, 25\end{array}$ \\
\hline $\begin{array}{l}\text { BugdayveDestek__ } \\
\text { MazotOrani }\end{array}$ &,- 520 &,- 559 &,- 006 & 1,000 &,- 265 &,- 226 &,- 813 &, 584 & $\begin{array}{r}- \\
47\end{array}$ \\
\hline $\begin{array}{l}\text { BugdayTohumOra } \\
\text { ni }\end{array}$ &,- 292 &,- 167 &,- 086 &,- 265 & 1,000 & ,998 & , 179 &,- 655 & $\begin{array}{r}, 27 \\
1\end{array}$ \\
\hline $\begin{array}{l}\text { BugdayveDestekTo } \\
\text { humOrani }\end{array}$ &,- 310 &,- 184 &,- 059 &,- 226 & ,998 & 1,000 & ,135 &,- 655 & $\begin{array}{r}, 28 \\
9\end{array}$ \\
\hline StokDegisimi & ,807 & ,841 &,- 566 &,- 813 & , 179 & ,135 & 1,000 &,- 674 & $\begin{array}{r}, 58 \\
1\end{array}$ \\
\hline $\begin{array}{l}\text { BugdayinTuketim } \\
\text { Mikltari }\end{array}$ &,- 490 &,- 602 &, 353 &, 584 &,- 655 &,- 655 &,- 674 & 1,000 & $\begin{array}{r}- \\
, 88\end{array}$ \\
\hline Verim & 686, & 763, &,- 258 &,- 471 & 271 & 289, & ,581 &,- 882 & $\begin{array}{r}2 \\
1,0 \\
00\end{array}$ \\
\hline
\end{tabular}

Tablo 4. Buğdayın Üretim Parametrelerine Ait Temel Bileşen Analizi 


\begin{tabular}{|c|c|c|c|c|c|c|c|}
\hline Bileșenler & & Ik Özdeğerler & & Kare Yüklen & elerin Çıkarn & na Toplamları & a \\
\hline & Toplam & $\%$ Varyans & Kümülatif \% & Toplam & $\%$ Varyans & Kümülatif \% & Toplam \\
\hline 1 & 4,770 & 53,004 & 53,004 & 4,770 & 53,004 & 53,004 & 4,676 \\
\hline 2 & 2,578 & 28,641 & 81,645 & 2,578 & 28,641 & 81,645 & 2,809 \\
\hline 3 & ,995 & 11,059 & 92,704 & & & & \\
\hline 4 & ,657 & 7,296 & 100,000 & & & & \\
\hline 5 & $4,000 \mathrm{E}-16$ & $4,445 \mathrm{E}-15$ & 100,000 & & & & \\
\hline 6 & $1,660 \mathrm{E}-16$ & $1,845 \mathrm{E}-15$ & 100,000 & & & & \\
\hline 7 & $6,328 \mathrm{E}-17$ & $7,031 \mathrm{E}-16$ & 100,000 & & & & \\
\hline 8 & $-9,593 \mathrm{E}-17$ & $-1,066 \mathrm{E}-15$ & 100,000 & & & & \\
\hline 9 & $-3,675 E-16$ & $-4,083 \mathrm{E}-15$ & 100,000 & & & & \\
\hline
\end{tabular}

\section{Kaynakça}

[1] https://data.tuik.gov.tr/Bulten/

[2] https://arastirma.tarimorman.gov.tr/tepge/Belgeler/

[3] Chen, M., Luo, Y., Shen, Y., Han, Z., \& Cui, Y. (2020). Driving force analysis of irrigation water consumption using principal component regression analysis. Agricultural Water Management, 234, 106089.

[4] Li, W., \& Huang, Y. (2020). A method for damage detection of a jacket platform under random wave excitations using cross correlation analysis and PCA-based method. Ocean Engineering, 214, 107734.

[5] Xu, M., Zhang, Y., Zhao, P., \& Liu, C. (2020). Study on aging behavior and prediction of SBS modified asphalt with various contents based on PCA and PLS analysis. Construction and Building Materials, 265, 120732.

[6] Wang, J., Shao, W., \& Kim, J. (2020). Analysis of the impact of COVID-19 on the correlations between crude oil and agricultural futures. Chaos, Solitons \& Fractals, 136, 109896.

[7] Zhang, X., Zhang, P., Yuan, X., Li, Y., \& Han, L. (2020). Effect of pyrolysis temperature and correlation analysis on the yield and physicochemical properties of crop residue biochar. Bioresource technology, 296, 122318.

[8] Utrilla-Vázquez, M., Rodríguez-Campos, J., AvendañoArazate, C. H., Gschaedler, A., \& Lugo-Cervantes, E. (2020). Analysis of volatile compounds of five varieties of Maya cocoa during fermentation and drying processes by Venn diagram and PCA. Food Research International, 129, 108834 .

[9] Zhang, X., He, L., Zhang, J., Whiting, M. D., Karkee, M., \& Zhang, Q. (2020). Determination of key canopy parameters for mass mechanical apple harvesting using supervised machine learning and principal component analysis (PCA). Biosystems Engineering, 193, 247-263.

[10] Petković, B., Petković, D., \& Kuzman, B. (2020). Adaptive neuro fuzzy predictive models of agricultural biomass standard entropy and chemical exergy based on principal component analysis. Biomass Conversion and Biorefinery, $1-11$.

[11] Yagmur, B., \& Gunes, A. (2021). Evaluation of the Effects of Plant Growth Promoting Rhizobacteria (PGPR) on Yield and Quality Parameters of Tomato Plants in Organic Agriculture by Principal Component Analysis (PCA). Gesunde Pflanzen, 73(2), 219-228.

[12] Pearson, K. (1901). LIII. On lines and planes of closest fit to systems of points in space. The London, Edinburgh, and Dublin philosophical magazine and journal of science, 2(11), 559-572.

[13] Cui, W., Sun, Z., Ma, H., \& Wu, S. (2020). The Correlation Analysis of Atmospheric Model Accuracy Based on the Pearson Correlation Criterion. In IOP Conference Series: Materials Science and Engineering (Vol. 780, No. 3, p. 032045).

[14] Weston, J., Elisseeff, A., Schölkopf, B., Tipping, M. (2003) Use of the zero norm with linear models and kernel methods. The Journal of Machine Learning Research, 3: 1439-1461.

[15] Deng, L., Pei, J., Ma, J. and Lee, D. L. (2004) A rank sum test method for informative gene discovery. In: Tenth Acm Sigkdd International Conference on Knowledge Discovery \& Data Mining. ACM.

[16] Crothers, L. M., Schreiber, J. B., Field, J. E., \& Kolbert, J. B. (2009). Development and Measurement Through Confirmatory Factor Analysis of the Young Adult Social Behavior Scale (YASB) An Assessment of Relational Aggression in Adolescence and Young Adulthood. Journal of Psychoeducational Assessment, 27(1), 17-28. 